\title{
Nanocellulose-Protein Matrices: A Model System for Controlled Drug Delivery
}

\author{
W. R. A. P. J. Ratnayake, ${ }^{1,4}$, J. W. Damunupola, ${ }^{2}$, S. Rajapakse ${ }^{3}$ and \\ A. C. A. Jayasundera ${ }^{4}$ \\ ${ }^{1}$ Postgraduate Institute of Science, University of Peradeniya, Sri Lanka \\ ${ }^{2}$ Department of Botany, Faculty of Science, University of Peradeniya, Sri Lanka \\ ${ }^{3}$ Department of Molecular Biology \& Biotechnology, Faculty of Science, University of \\ Peradeniya, Sri Lanka \\ ${ }^{4}$ Department of Chemistry, Faculty of Science, University of Peradeniya, Sri Lanka
}

\begin{abstract}
Bacterial nanocellulose (BNC) has been widely using for various applications in bionanomedicine since decades. Therefore, present study focused towards a systematic investigation of identifying the applicability of freeze-dried bacterial nanocellulose (fd-BNC) synthesized by Gluconacetobacter spp. as drug delivery matrix for proteins using Bovine Serum Albumin (BSA). BSA was chosen as a model drug due to its high-water solubility, abundance, good stability and wide acceptance. BNC is inherited with superior mechanical (high tensile strength), chemical (hydrophilicity, high degree of polymerization, crystallization) and biological (non-cytotoxicity, nonbiodegradable, high purity) properties. The different BSA concentrations of 2, 5, 10, $20(\mathrm{mg} / \mathrm{ml})$ dissolved in Phosphate Buffered Saline (PBS) adsorbed and released from pre-swelled BNC hydrogel at predetermined time points under shaking conditions of room temperature were examined. UV absorbance spectrometry was used in analyzing loading and releasing profiles. The loading profile demonstrated mean loaded BSA amounts of $1.65( \pm 0.11), 3.02( \pm 0.41), 7.04( \pm 0.66)$, $13.52( \pm 0.53)(\mathrm{mg})$ after 48 hours for 2, 5, 10, $20(\mathrm{mg} / \mathrm{ml})$ respectively. Regression coefficient $\left(\mathrm{r}^{2}\right)$ of equilibrium loading isotherm was 0.9965 . Higher BSA adsorption is due to the fine network of nanofiber structure in BNC. Drug loading stabilized after initial 8 hours and was controlled mainly by diffusion whereas no saturation effects observed. Release profile indicated a 'burst release' during initial 8 hours followed by a controlled release. The mean released amount of 2, 5, 10, $20(\mathrm{mg} / \mathrm{ml})$ BSA concentrations were $1.12( \pm 0.19), 2.89( \pm 0.27), 5.59( \pm 0.44)$ and $10.37( \pm 0.53)(\mathrm{mg})$ respectively. Diffusion exponent (n) values were $0.65,0.67,0.79,0.69$ for $2,5,10,20(\mathrm{mg} / \mathrm{ml})$ BSA. Ritger-Peppas Power law model suggested, the drug transport mechanism of studied BSA-fd-BNC system is non-Fickian (anomalous) in which overlay of diffusion and swelling controlled release is observed. Overall, this study suggests the potentials of BNC as a suitable carrier for the controlled delivery of active protein drugs like BSA.
\end{abstract}

Keywords: Bacterial nanocellulose, controlled release, Bovine Serum Albumin, anomalous diffusion

\section{Introduction}

Bacterial nanocellulose (BNC) is produced as same as cellulose through condensation polymerization of anhydroglucose units by $\beta$-1,4-glycosidic linkage by a bacterial species known as Gluconacetobacter xylinus. Bacterial cellulose (BC) inherited with excellent mechanical, chemical and biological properties compared with plant cellulose rendering it as an outstanding biopolymer in many biomedical applications such as artificial blood vessels, scaffolds for tissue engineering, antimicrobial wound dressing, temporary skin, connective tissue replacements and drug delivery. $\mathrm{BC}$ is known to have high surface area, wet tensile strength, high purity and 
more importantly composed of nanofibers typically ranging from a diameter of 40-60 nm and approximately 100 times thinner than the fibers of plant cellulose (Dufresne, 2014). Other than that, BC is bio compatible (resembles to collagen), non-toxic, non-biodegradable in human body, flexible and has a porous nanofiber network structure. Bovine serum albumin (BSA) Fraction V is used as the protein model drug for studying the loading and releasing into a porous network of BNC because of its medically important, unusual ligand binding properties, highly available, low cost and structural homology with human serum albumin. Nowadays polypeptide and protein drugs are gaining a significant interest than the conventional therapeutics as it ranges within a wide spectrum including bacterial or plant toxins, hormones and growth factors, anticoagulants and clotting factors, drug-activating enzymes and antibody-based drugs (Katsila et al, 2012).

Although the fine network structure of $\mathrm{BNC}$ is expected to hold a high amount of drug molecules due to its large surface area; up to now only a limited number of reports describing BNC as delivery system for the controlled release of drugs are available. Only the drug loaded BNC wound care products reached the market (e.g. antiseptic polyhexamethylene biguanide) (Muller et al, 2013). Compared with other traditional hydrogels applied in wound care, BNC hydrogel possess mechanically superior stability. In the present study the systematic investigation of loading and release of proteins on freeze- dried BNC hydrogels and commercially available plant cellulose / microcrystalline cellulose (MCC) hydrogels using bovine serum albumin as a model drug was carried out. The study focused on proteins since they are introduced into the market as an increasing part of pharmaceutical compounds with growing interest as additives in medical devices like growth factors, antibodies for wound healing or cell attractants for tissue engineering.

\section{Materials and Methods}

\section{Preparation of freeze-dried BNC hydrogel}

Due to the unavailability of the pure culture of G. xylinus the method described by Ratnayake and Liyanage, 2016a was used to isolate the bacterium species from pineapple peel residue and cultured in the specific medium Hestrin-Schramm (HS). Synthesized BNC fibers were extracted by centrifugation and purified boiling with $2 \%$ (w/w) Sodium hydroxide. The resulting nanofibers were lyophilized for 48 hours. BNC was preswollen in $10 \mathrm{ml}$ of distilled water at room temperature under shaking conditions (70 rpm) for three hours before loading.

\section{Preparation of 100 mM Phosphate Buffered Saline (PBS)}

One liter of PBS was prepared starting with $800 \mathrm{ml}$ of distilled water and adding $8 \mathrm{~g}$ of $\mathrm{NaOH}, 0.2 \mathrm{~g} \mathrm{of} \mathrm{KCl}$, $1.44 \mathrm{~g}$ of $\mathrm{Na}_{2} \mathrm{HPO}_{4}$ and $0.24 \mathrm{~g}$ of $\mathrm{KH}_{2} \mathrm{PO}_{4}$. The $\mathrm{pH}$ was adjusted to $7.4 \mathrm{using} \mathrm{HCl}$. Then distilled water added to reach the final volume.

\section{Drug loading and releasing}

A series of bovine serum albumin (BSA, fraction V; WINLA) was used for the calibration $(0.1,0.2,0.5,1,2$ $\mathrm{mg} / \mathrm{ml} \mathrm{BSA}$ ) dissolved in PBS buffer. The two hydrogels (fd-BNC) and MCC were dipped in $10 \mathrm{ml}$ of $0.1 \mathrm{M}$ PBS containing 2, 5, 10, $20 \mathrm{mg} / \mathrm{ml}(\mathrm{w} / \mathrm{v}) \mathrm{BSA}$ and drug loading was carried out at $25{ }^{\circ} \mathrm{C}$ in a shaking water bath (70 rpm) for predetermined time points up to 48 hours $(0.25,0.5,1,2,3,4,5,6,8,24,30$ and 48 hours). All samples were run in triplicate. A small aliquot from the supernatant was drawn out and the BSA concentration measured using UV spectrometry at $278 \mathrm{~nm}$. Absorbance values of stock BSA (2, 5, 10, $20 \mathrm{mg} / \mathrm{ml})$ were also measured simultaneously with sample measurements. BNC and MCC samples incubated in PBS without BSA and BSA solution without BNC and MCC were used as controls. The amount of loaded drug was calculated using the difference in the initial solution and supernatant referring to the calibration curve. 
The amount of drug release was investigated by removing BSA loaded nanocellulose hydrogel samples at each incubation time point and transferring them into $10 \mathrm{ml}$ of fresh PBS as the release medium. Drug release was examined at room temperature $\left(25^{\circ} \mathrm{C}\right)$ under shaking $(70 \mathrm{rpm})$. A small aliquot from the supernatant was drawn out from the release medium at the specified time intervals $(0.25,0.5,1,2,3,4,5,6,8,24,30$ and 48 hours) and checked for the UV absorbance at $278 \mathrm{~nm}$. Finally, the concentration of released drug was calculated by UV absorbance measurements at $278 \mathrm{~nm}$.

\section{Data Analysis}

\section{Investigation of the degree of preswelling}

Percentage water absorption was determined using following equation and samples were preswollen for 1, 2, 3, 8 and 24 hours in distilled water before loading experiments. Water absorbed BNC data were analyzed using one-way ANOVA at $95 \%$ confidence interval (Tukey comparison test) to identify the swelling behavior of freeze-dried BNC.

$$
\mathrm{w}_{\mathrm{c}}(\%)=\left(\mathrm{m}_{\mathrm{w}}-\mathrm{m}_{\mathrm{d}}\right) / \mathrm{m}_{\mathrm{w}} \times 100
$$

Equation $\mathrm{m}_{\mathrm{w}}$ represents the weight of the wet swollen BNC hydrogel whereas $\mathrm{m}_{\mathrm{d}}$ is the weight of the freezedried material. Data were analyzed using Minitab® 17.1.0 software.

\section{Mathematical analysis of dug release}

Drug release data were analyzed using power law model (Muller et al, 2013).

$$
\mathrm{M}_{\mathrm{t}} / \mathrm{M}_{\infty}=\mathrm{kt}^{\mathrm{n}}
$$

Where $\mathrm{M}_{\mathrm{t}}$ and $\mathrm{M}_{\infty}$ are absolute cumulative amounts of drug released at time $\mathrm{t}$ and infinity respectively and $\mathrm{k}$ is a constant incorporating structural and geometrical characteristics of the device and $\mathrm{n}$ is the exponent from which the mechanism of drug release is derived. The equation was used to fit release data in 5-60\% range. The $n$ values were calculated from slope of the $\log \left(\mathrm{M}_{\mathrm{t}} / \mathrm{M}_{\infty} * 100\right)$ against $\log (\mathrm{t})$. Loading and releasing data were analyzed using SigmaPlot (12.5.0.38).

\section{Results and Discussion}

\section{Preparation of BNC hydrogels}

The advancements in biopolymer research during last decade have clearly stated the significance and potentials of biopolymers for diverse applications, particularly for biopolymers synthesized by microorganisms, including bacterial nanocellulose (BNC). Variety of BNCs have been fabricated for different applications in biomedicine like drug delivery systems, tissue regeneration, vascular grafts and scaffolds in tissue engineering in vitro and in vivo (Czaja et al, 2007). Extensive researches have been steering to improve the production and modify this marvelous biopolymer to comply with emerging applications in green nanotechnology as a good solution for replacing hazardous chemically synthesized inorganic nanoparticles up to some extent. In this study an alternative culture of G. xylinus was used due to the unavailability of pure culture which derived from waste pineapple peel residue and maintained in specific culture media called HS broth (Hestrin-Schramm medium) under static culture conditions. The culture conditions for the alternative pineapple peel culture such as TSS 
(Total Soluble Solids, pH and inoculation ratio) were optimized and published during previous studies (Ratnayake and Liyanage, 2016a).

\section{Wavelength Analysis and BSA calibration}

Bovine Serum Albumin is medically important and widely used as a standard in proteomics. Recent studies suggested its significance as an anticancer drug since ribosylation of BSA resulting in Reactive Oxygen Species (ROS) accumulate and killing the breast cancer, MCF-7 in vitro culture cell lines (Khan et al, 1990). This protein also has a high concentration of sulphur amino acids and glutamylcysteine, both of which are precursors for glutathione (Bounous, 2000). Glutathione is a super antioxidant made in the body. It is capable of recycling other antioxidants so that they can be reused by the body.

A wavelength analysis was performed to determine the specific wavelength of UV absorbance by using a standard series of BSA. The standard BSA series $(0.2,0.5,1,2 \mathrm{mg} / \mathrm{ml} \mathrm{BSA})(\mathrm{w} / \mathrm{v})$ absorbed UV radiation specifically at $278 \mathrm{~nm}$ as shown in figure 1 . The strong absorption peak at around $278 \mathrm{~nm}$ is due to the aromatic amino acids (tryptophan, tyrosine and phenylalanine).

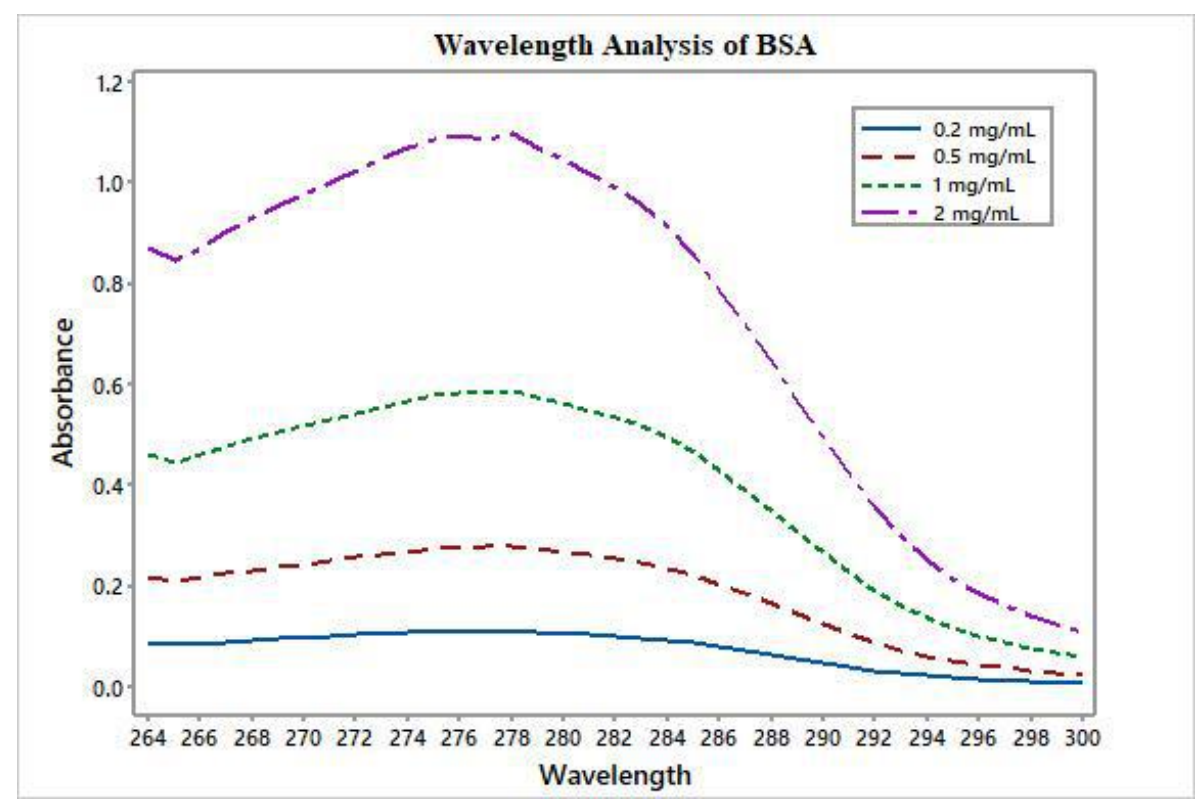

Figure 1: Wavelength Analysis of BSA 
For determining the quantity of loaded BSA during each incubation time point a calibration chart was used. Figure 2 illustrates the calibration plot of BSA drawn using $0.1,0.2,0.5,1,2 \mathrm{mg} / \mathrm{ml}$ BSA series. The calibration was run in triplicate and repeated once.

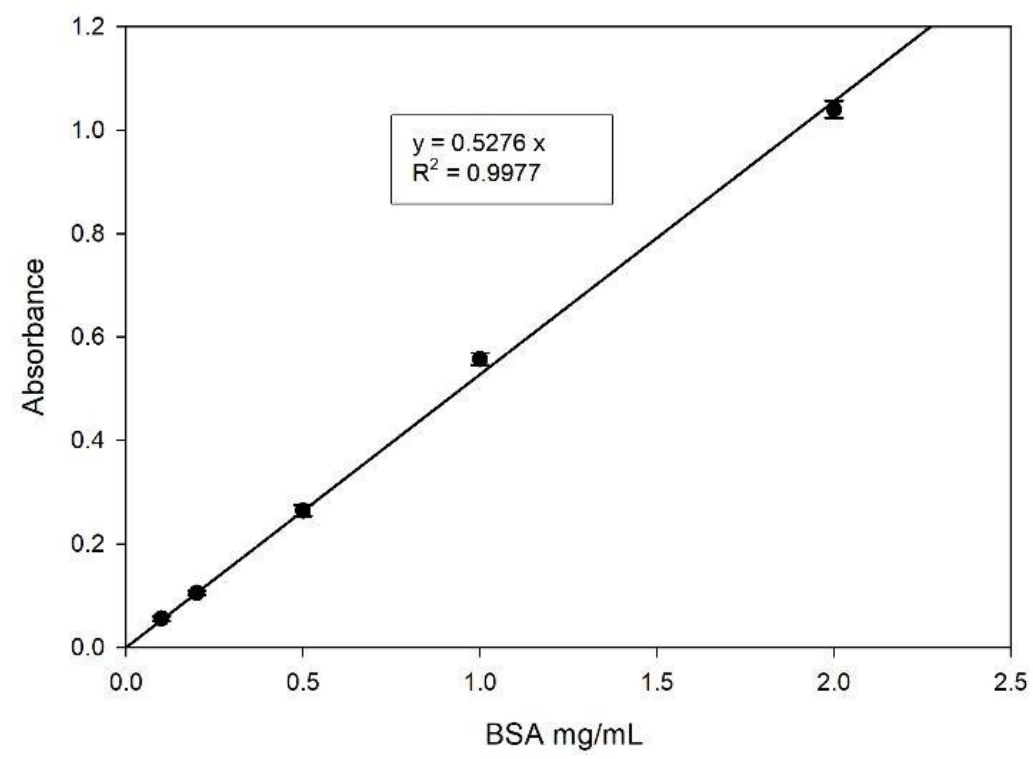

Figure 2: Calibration of BSA

The linear regression coefficient $\left(\mathrm{r}^{2}\right)$ is 0.99 . Calibration curve complies with Beer-Lambert Law as the range lies between 0.2 to 0.8 . The amount of loaded BSA was calculated from the difference between the amount of protein in the loading solution (refer the calibration plot of BSA) and the amount of BSA in the supernatant at each incubation time point.

Two different types of nanocellulose hydrogels referred as freeze-dried BNC hydrogel (fd-BNC) and commercially available native/plant cellulose/micro crystalline cellulose (MCC) also used for examining their loading and releasing capacity for the BSA. The bacterial nanocellulose is prepared by using an alternative culture of G. xylinus derived from pineapple peel residue Moreover, these BNC and MCC nanofibers were extensively characterized using Fourier Transform Infrared Spectroscopy (FTIR), Particle Size Analysis (PSA), Scanning Electron Microscopy (SEM) and Powder X-ray Diffraction (PXRD) and published in previous studies (Ratnayake et al, 2016b).

\section{Drug Loading}

The mechanism of drug loading and releasing from a polymeric hydrogel is governed by two factors, swelling and diffusion. Therefore, to find out the influence of swelling freeze-dried BNC (fd-BNC) and MCC samples were preswollen before drug loading. Then the preswelled hydrogels of fd-BNC and MCC samples were used for the investigation of loading and releasing of the model drug (BSA). Swelled freeze-dried BNC hydrogel sample is shown in figure 3 . 


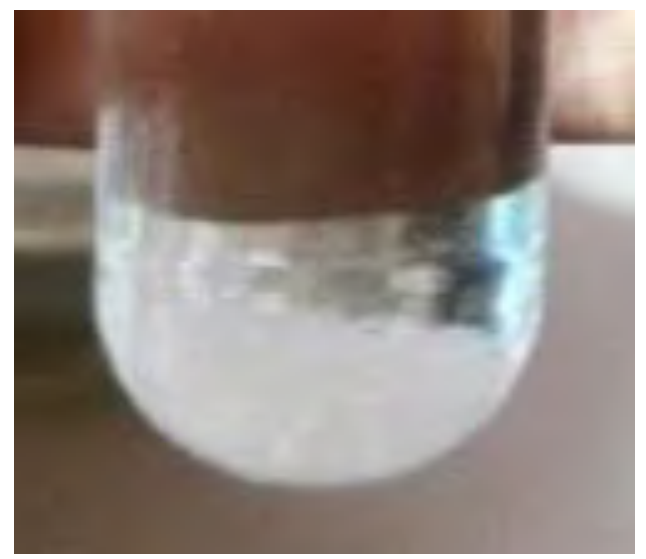

Figure 3: Preswollen fd-BNC hydrogel

To determine the degree of preswelling, the prepared hydrogel samples were dipped in $10 \mathrm{ml}$ of distilled water for 24 hours. Variation in swelling versus predetermined time intervals was analyzed and results are depicted in figure 4.

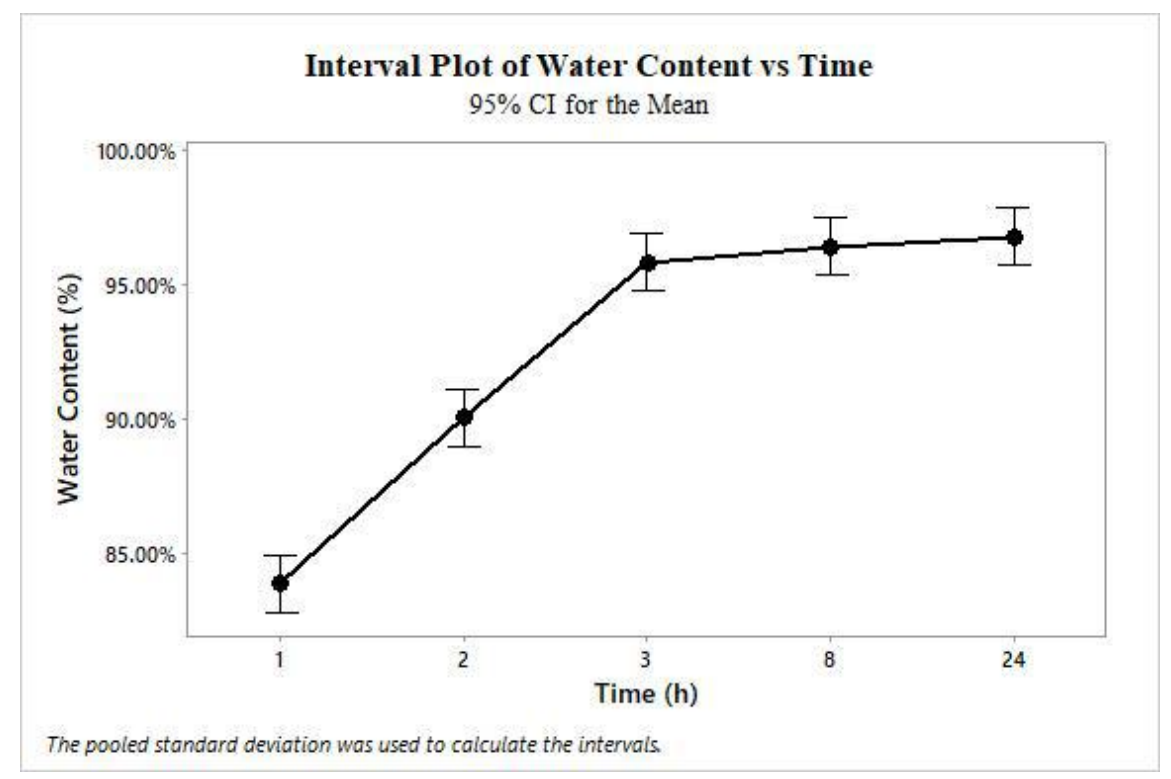

Figure 4: Variation of water absorption into fd-BNC with time

After 3 hours $95.91 \%$ of mean water content absorbed into fd-BNC hydrogel. Therefore, one way-ANOVA (Tukey comparison) was used to analyze whether there is a significant difference between the time intervals of swelling. The results gave that there is no significant difference between 3-24 hour time intervals as shown in figure 5 . 


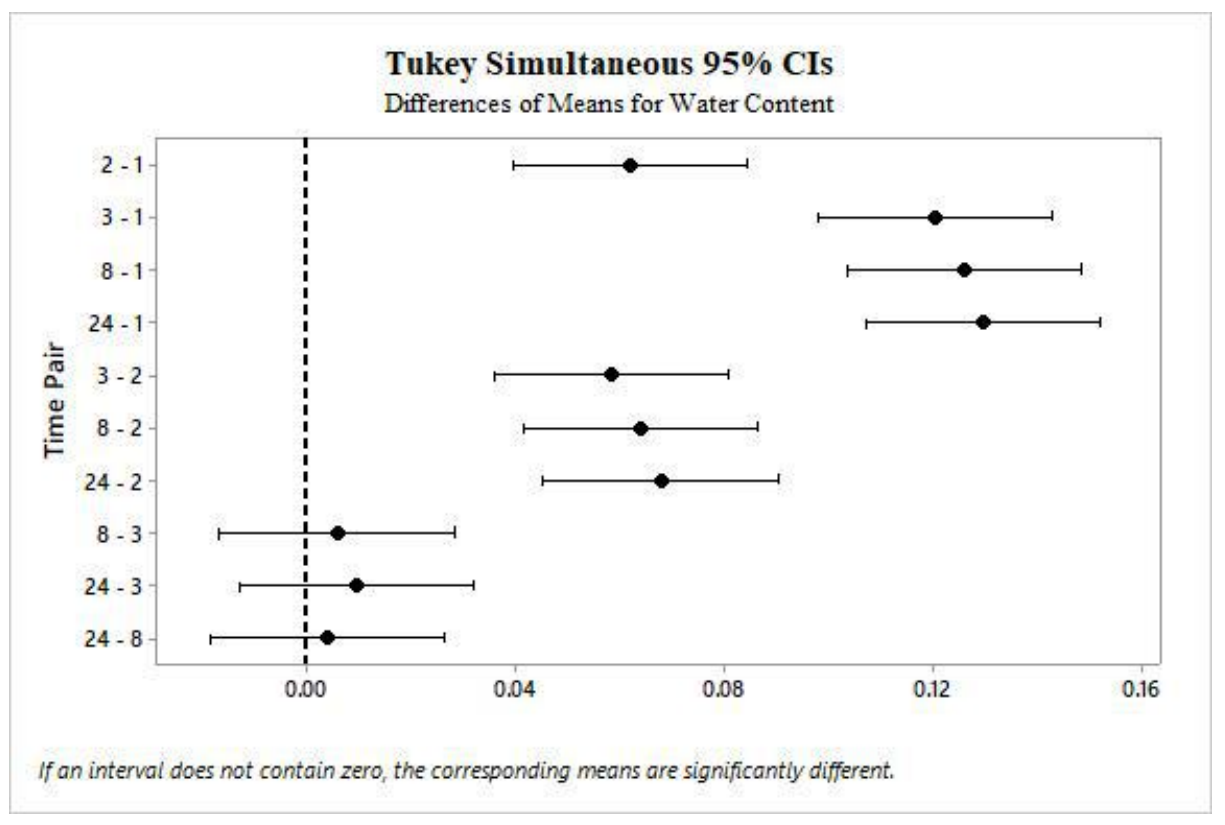

Figure 5: Comparison study of swelling time intervals

Swelling generally refers to the uptake of water by a polymer system with volume expansion. BNC is a hydrogel and imbibe water many times than its weight in water. Bacterial nanocellulose has a high compatibility to water due to its hydrogen bond structure and water enters into nanocellulose relatively rapidly. Therefore, the hydrophilicity of BNC imbibes water significantly at higher rate as shown in figure 4. The duration of swelling is not seemed to be interfere with the amount of total protein released. Consequently, preswelling was carried out for 3 hours for all experimental designs.

Preswollen freeze dried BNC (fd-BNC) and microcrystalline cellulose (MCC) hydrogel samples were loaded in PBS buffer $\mathrm{pH} 7.4$ supplemented with different BSA concentrations $(2,5,10,20 \mathrm{mg} / \mathrm{ml})(\mathrm{w} / \mathrm{v})$ for predetermined time intervals $(0.25,0.5,1,2,3,4,5,6,8,24,30,48$ hour $)$ at room temperature submersed under shaking. The time and concentration dependency of BSA loading into fd-BNC and MCC hydrogels were investigated and fitted into a three-parameter logarithmic function as shown in figure 6 . 

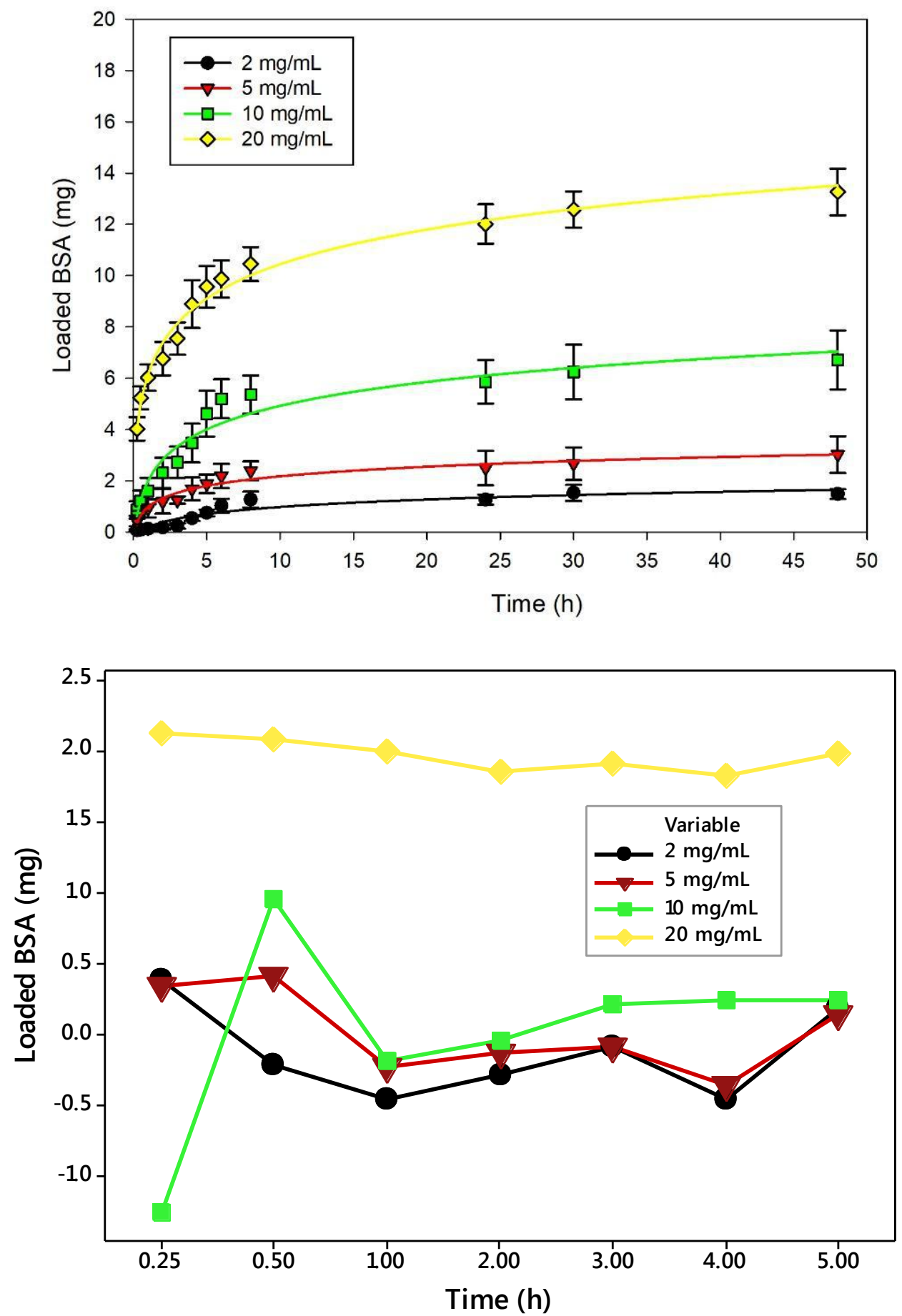

Figure 6: Time and concentration dependency of BSA loading into freeze-dried bacterial nanocellulose (fd-BNC) (a) and microcrystalline cellulose (MCC) (b) fitted by a threeparameter logarithmic function (Data calculated as mean $\pm S D, n=3$ ) 
According to figure 6(a) fd-BNC shows a well characteristic increase in protein uptake with higher BSA concentrations from 2 to $20 \mathrm{mg} / \mathrm{ml}$ and figure 6(b) clearly shows that there is no distinguishable loading pattern of BSA into native/plant nanocellulose (MCC) when compared to BNC. The difference for the protein uptake of hydrogels was due to the structural changes in the two types of nanocelluloses. Bacterial nanocellulose has an excellent nanofiber structure (a matrix of interwoven nanofibrils) while plant cellulose has a poor arrangement of nanofibers. The changes in the properties of two nanocelluloses were investigated and confirmed in previous studies with the use of advanced instrumental techniques (Ratnayake et al, 2016b). As there was no clear pattern of BSA loading into MCC, only BNC was used for further steps in drug release. The loading of BSA into BNC hydrogel is higher during initial 8 hours followed by a lower adsorption thereafter. Figure 7 illustrates the loading isotherm obtained by plotting the amount of loaded protein $(\mathrm{mg})$ per sample dry weight $(\mathrm{g})$ against the respective equilibrium concentration of loading buffer.

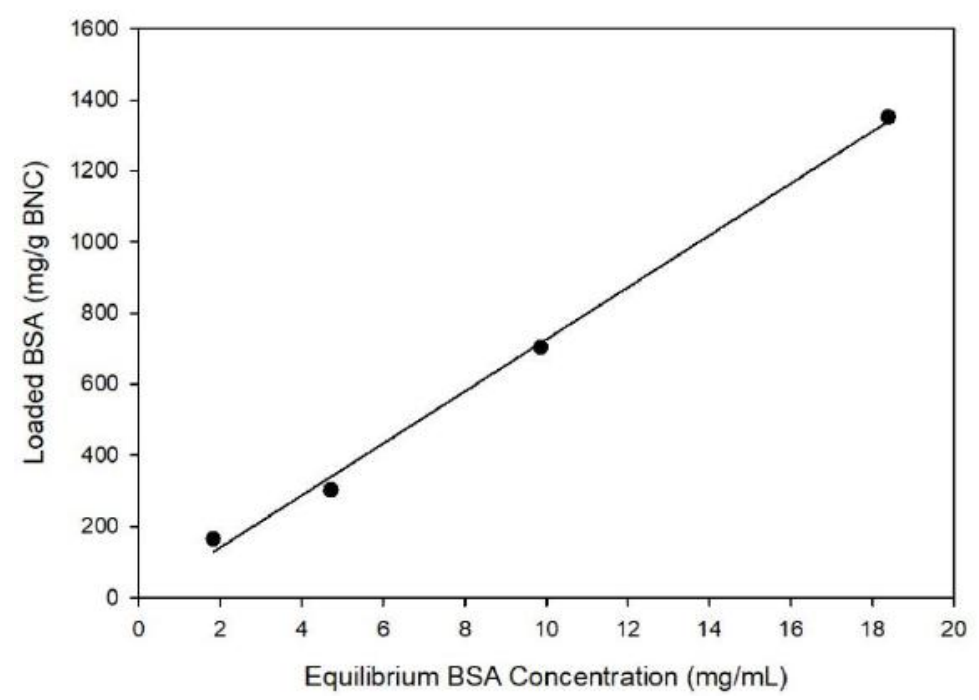

Figure 7: Equilibrium Adsorption isotherm offd-BNC

According to figure 6(a) mean loaded BSA (mg) after 48 hours were 1.65, 3.02, 7.04, 13.52 for 2, 5, 10 and 20 $(\mathrm{w} / \mathrm{v})$ BSA. The loading isotherm also suggests the linear correlation between loaded BSA (mg/g BNC) with equilibrium BSA concentration $(\mathrm{mg} / \mathrm{ml})$ giving a regression coefficient of $\left(\mathrm{r}^{2}\right)$ of 0.9965 . The linearity between solute weight fraction versus solute concentration in the loading bath is found to be in accordance with literature (Haimer et al, 2010). The adsorption of BSA into BNC hydrogel is diffusion controlled and no saturation effects were observed under the selected conditions. Furthermore, adsorption of BSA into BNC nanofiber network is due to physical adsorption (physisorption) which doesn't involve covalent linkages. The loading percentage (loaded protein as percentage of sample initial dry weight) is in the range $16.48-135.18 \%$ in $2-20 \mathrm{mg} / \mathrm{ml}$ loading solutions respectively. This process is controlled by loading time and initial protein concentration in the loading medium. 


\section{Drug release}

Drug release is an important topic in drug delivery field for decades. With the developments in material design and engineering, innovative materials with increasing complexity together with advanced functions have been introduced into the impending drug delivery systems and devices. 'Drug release' denotes the process in which drug molecules (solutes) migrate from the initial position in the polymeric system to the polymer's outer surface and then to the release medium. The drug loaded BNC samples were removed and transferred into test tubes containing $10 \mathrm{ml}$ of fresh PBS pH 7.4 and amount of the released BSA was determined using UV visible spectrometry at $278 \mathrm{~nm}$ over 48 hours. The cumulative amounts of released BSA from BNC hydrogel as a function of time and concentration is illustrated in figure 8.

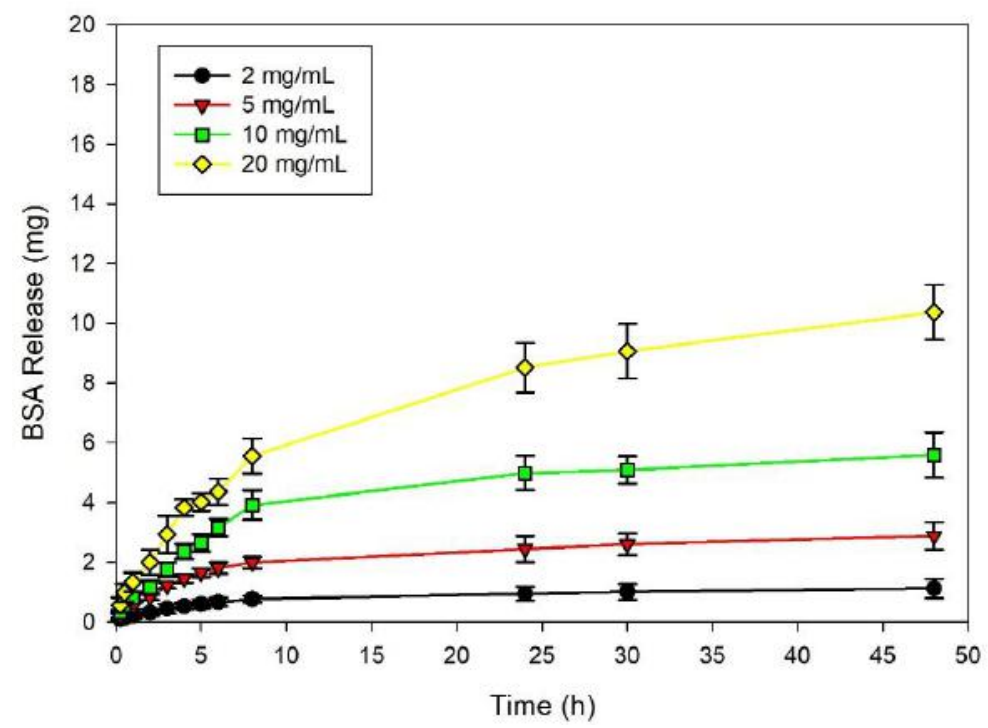

Figure 8: BSA release of fd-BNC samples, (Data calculated as mean $\pm S D n=3$ )

The cumulative release data in figure 8 indicates an exponential curve with a rapid 'burst' release in the initial 8 hours followed by a slow release rate up to 48 hours. The burst release is more prominent when increasing the protein concentration, explaining the concentration dependency. Table 1 illustrates the loaded and released quantities as a percentage of initial BSA amount in loading medium (w/v).

Table 1: Percentage uptake capacity and released quantity of BSA after 48 hours

\begin{tabular}{lllll}
\hline $\begin{array}{l}\text { BSA concentration } \\
(\mathrm{mg} / \mathrm{ml})\end{array}$ & $\begin{array}{l}\text { Loaded amount } \\
(\mathrm{mg})\end{array}$ & $\begin{array}{l}\text { Loading }(\mathrm{w} / \mathrm{v} \\
\%)\end{array}$ & $\begin{array}{l}\text { Released amount } \\
(\mathrm{mg})\end{array}$ & $\begin{array}{l}\text { Releasing (w/v } \\
\%)\end{array}$ \\
\hline 2 & 1.65 & 82.39 & 1.12 & 68.11 \\
5 & 3.02 & 60.49 & 2.89 & 95.41 \\
10 & 7.04 & 70.39 & 5.59 & 79.48 \\
20 & 13.52 & 67.59 & 10.37 & 76.75 \\
\hline
\end{tabular}

When referring to table 8 , all samples have released a significant amount of loaded BSA after 48 hours. Therefore, it is confirmed that BNC could act as a potential carrier for the drug; releasing BSA rapidly during initial 8 hours followed by a controlled release to maintain the drug concentration overtime. Drug loading into the hydrogel is faster than release due to the higher concentration gradient on the loading bath which leads to 
faster diffusion. This characteristic feature of BNC makes it suitable as a drug carrier for applications such as wound dressing, transdermal drug delivery and drug hydrogels.

\section{Drug loading and releasing results (BSA-fd-BNC system)}

Table 2: Loading statistics (values are shown in $m g$ and data calculated as mean $\pm S D, n=3$ )

\begin{tabular}{lllll}
\hline Time $(\mathrm{h})$ & $2 \mathrm{mg} / \mathrm{ml}$ & $5 \mathrm{mg} / \mathrm{ml}$ & $10 \mathrm{mg} / \mathrm{ml}$ & $20 \mathrm{mg} / \mathrm{ml}$ \\
\hline 0.25 & $0.07 \pm 0.04$ & $0.42 \pm 0.21$ & $0.86 \pm 0.34$ & $4.02 \pm 0.45$ \\
0.50 & $0.09 \pm 0.05$ & $0.66 \pm 0.35$ & $1.22 \pm 0.40$ & $5.23 \pm 0.45$ \\
1 & $0.13 \pm 0.06$ & $0.92 \pm 0.35$ & $1.60 \pm 0.52$ & $6.02 \pm 0.51$ \\
2 & $0.17 \pm 0.09$ & $1.19 \pm 0.48$ & $2.31 \pm 0.59$ & $6.76 \pm 0.65$ \\
3 & $0.24 \pm 0.11$ & $1.24 \pm 0.14$ & $2.72 \pm 0.61$ & $7.54 \pm 0.63$ \\
4 & $0.53 \pm 0.10$ & $1.68 \pm 0.44$ & $3.47 \pm 0.75$ & $8.89 \pm 0.93$ \\
5 & $0.74 \pm 0.13$ & $1.88 \pm 0.36$ & $4.61 \pm 0.89$ & $9.57 \pm 0.81$ \\
6 & $1.03 \pm 0.27$ & $2.19 \pm 0.47$ & $5.20 \pm 0.76$ & $9.87 \pm 0.72$ \\
8 & $1.27 \pm 0.31$ & $2.38 \pm 0.37$ & $5.35 \pm 0.75$ & $10.46 \pm 0.67$ \\
24 & $1.26 \pm 0.19$ & $2.50 \pm 0.67$ & $5.86 \pm 0.85$ & $12.02 \pm 0.77$ \\
30 & $1.53 \pm 0.31$ & $2.66 \pm 0.63$ & $6.25 \pm 1.06$ & $12.59 \pm 0.71$ \\
48 & $1.48 \pm 0.19$ & $3.02 \pm 0.72$ & $6.71 \pm 1.14$ & $13.27 \pm 0.91$ \\
\hline
\end{tabular}

Table 3: Releasing statistics (values are shown in $\mathrm{mg}$ and data calculated as mean $\pm S D, n=3$ )

\begin{tabular}{lllll}
\hline Time $(\mathrm{h})$ & $2 \mathrm{mg} / \mathrm{ml}$ & $5 \mathrm{mg} / \mathrm{ml}$ & $10 \mathrm{mg} / \mathrm{ml}$ & $20 \mathrm{mg} / \mathrm{ml}$ \\
\hline 0.25 & $0.10 \pm 0.06$ & $0.19 \pm 0.08$ & $0.34 \pm 0.06$ & $0.57 \pm 0.25$ \\
0.5 & $0.14 \pm 0.05$ & $0.31 \pm 0.09$ & $0.57 \pm 0.12$ & $0.98 \pm 0.30$ \\
1 & $0.21 \pm 0.09$ & $0.52 \pm 0.12$ & $0.81 \pm 0.15$ & $1.33 \pm 0.32$ \\
2 & $0.32 \pm 0.12$ & $0.84 \pm 0.09$ & $1.16 \pm 0.25$ & $2.00 \pm 0.42$ \\
3 & $0.45 \pm 0.16$ & $1.22 \pm 0.10$ & $1.76 \pm 0.23$ & $2.93 \pm 0.62$ \\
4 & $0.53 \pm 0.12$ & $1.46 \pm 0.14$ & $2.36 \pm 0.25$ & $3.83 \pm 0.28$ \\
5 & $0.60 \pm 0.15$ & $1.65 \pm 0.15$ & $2.65 \pm 0.28$ & $4.01 \pm 0.30$ \\
6 & $0.67 \pm 0.14$ & $1.81 \pm 0.19$ & $3.16 \pm 0.29$ & $4.36 \pm 0.44$ \\
8 & $0.77 \pm 0.11$ & $1.99 \pm 0.20$ & $3.91 \pm 0.49$ & $5.56 \pm 0.58$ \\
24 & $0.95 \pm 0.23$ & $2.44 \pm 0.44$ & $4.99 \pm 0.57$ & $8.51 \pm 0.84$ \\
30 & $1.01 \pm 0.26$ & $2.60 \pm 0.36$ & $5.09 \pm 0.45$ & $9.07 \pm 0.92$ \\
48 & $1.12 \pm 0.33$ & $2.89 \pm 0.47$ & $5.59 \pm 0.76$ & $10.37 \pm 0.92$ \\
\hline
\end{tabular}




\section{Mathematical analysis of drug release}

Ritger-Peppas and Korsmeyer-Peppas model (Power law) is a more comprehensive, semi-empirical equation to describe the drug release from a polymeric matrix, ideally a hydrogel. It is a widely accepted mathematical model for polymeric hydrogels including more than one type of drug transport mechanism (Korsmeyer et al, 1983). The log function of the original equation is used and shown below.

$$
\log \left(M_{t} / M_{\infty}\right)=\log k+n \log t
$$

Exponential drug release curves suggest that release kinetics of studied system is mainly driven by diffusion. Then release data were fitted to power law model and depicted in figure 9.

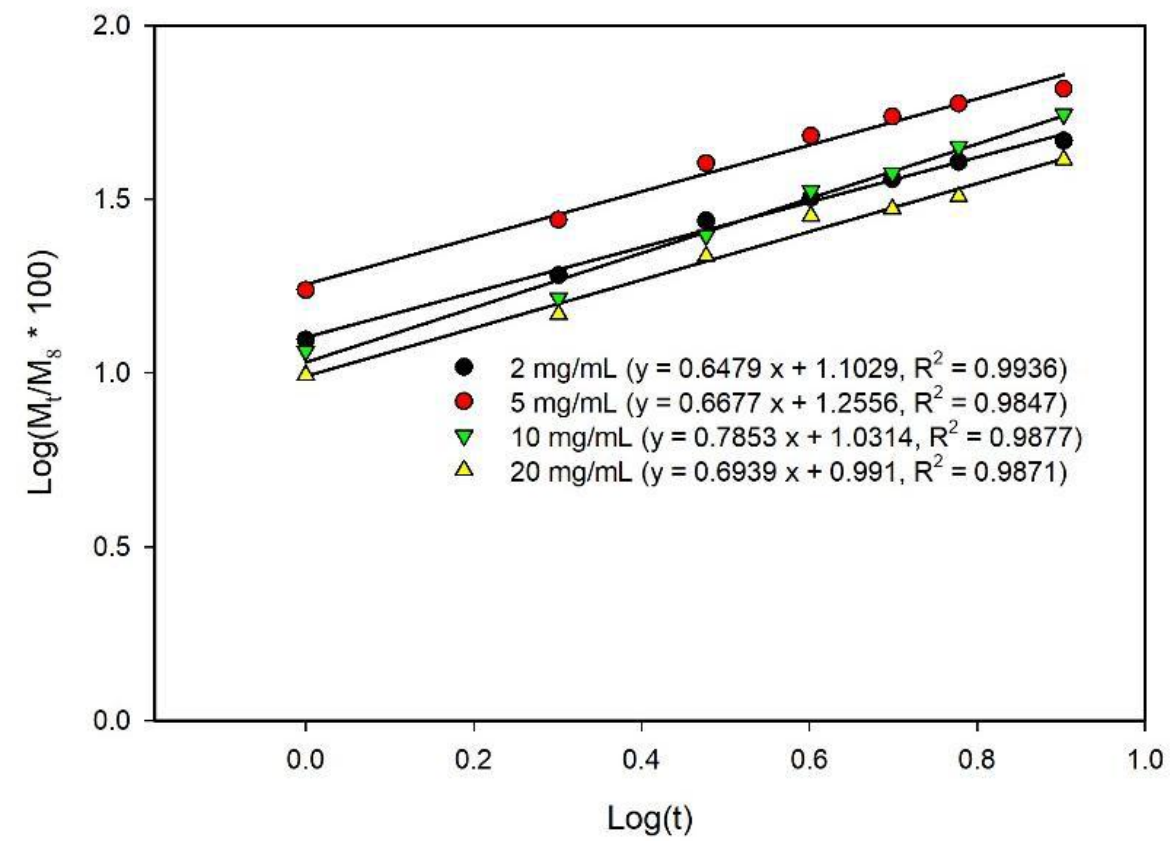

Figure 9: Plot of power law model (Data calculated as mean $\pm S D: n=3$ )

Modeling was applied for 2, 5, $1020(\mathrm{mg} / \mathrm{ml})$ BSA release data that is ranging from 5-60\% and $\mathrm{n}$ values were calculated and summarized in table 4.

Table 4: Mathematical analysis of drug release from BSA-fd-BNC system

\begin{tabular}{llll}
\hline $\begin{array}{l}\text { Sample type } \\
\text { BSA }(\mathrm{mg} / \mathrm{ml})\end{array}$ & Power law equation & $\begin{array}{l}\text { Diffusional exponent } \\
(\mathrm{n})\end{array}$ & $\begin{array}{l}\text { Regression coefficient } \\
\left(\mathrm{r}^{2}\right)\end{array}$ \\
\hline 2 & $\mathrm{y}=0.6479 \mathrm{x}+1.1029$ & 0.65 & 0.9936 \\
5 & $\mathrm{y}=0.6677 \mathrm{x}+1.2556$ & 0.67 & 0.9847 \\
10 & $\mathrm{y}=0.7853 \mathrm{x}+1.0314$ & 0.79 & 0.9877 \\
20 & $\mathrm{y}=0.6939 \mathrm{x}+0.991$ & 0.69 & 0.9871 \\
\hline
\end{tabular}

In the study calculated $\mathrm{n}$ values fell between $0.5<\mathrm{n}<1$ for all samples indicating non-Fikian or anomalous diffusion model and exponent values are in accordance with drug delivery system incorporating a cylindrical 
polymeric system (Ritger and Peppas, 1987). Results also indicated the shape of the polymeric system; bacterial nanocellulose, a fiber which has a geometry of a cylinder (length and width). Although both swelling and diffusion play a role in the drug release of BSA-fd-BNC system, the anomalous transport of the studied system represents that solvent diffusion velocity and bacterial nanocellulose polymer relaxation (preswelling) possess same magnitudes. Similar release behavior was obtained by other reports describing poly (vinyl ether)-based hydrogels which also deviates from Fikian mode (Guemuesderelioglu and Kesgin, 2005).

\section{Conclusion}

A model system to investigate drug loading and releasing was carried out using bacterial nanocellulose hydrogel and a model protein drug bovine serum albumin. The results of UV absorbance at $278 \mathrm{~nm}$ revealed a well characteristic pattern for the loading and release profiles in the BSA-fd-BNC system. Adsorption as well as the release of the drug from the polymer matrix depended on the concentration gradient and no saturation effects observed. A burst release was observed during initial 8 hours followed by a controlled release up to 48 hours. The power law model was applied to study the release kinetics which indicated a non Fickian or anomalous diffusion for the drug- polymer system. This study demarcates the importance of BNC as a suitable carrier for protein drugs like BSA. All in all, study highlights the potentials of a non-toxic, non- biodegradable and bio compatible controlled drug release system for the emerging applications in bio-nanomedicine.

\section{References}

Bounous, G., 2000, Whey protein concentrate (WPC) and glutathione modulation in cancer treatment, Anticancer Research, 20:4785-4792

Czaja, W., Krystynowicz, A., Bielecki, S., Malcom, B., 2006, Microbial cellulose- the natural power to heal wounds, Journal of Biomaterials, 27:145-151

Dufresne, N. L.A., 2014, Nanocellulose in biomedicine: Current status and future prospect, European Polymer Journal, 59:302-325

Guemuesderelioglu, M., Kesgin, D., 2005. Release kinetics of bovine serum albumin from pH-sensitive poly(vinyl ether) based hydrogels, International Journal of Pharmaceutics, 288(2):273-279

Haimer, E., Wendland, M., Schlufter, K., Frankenfeld, K., Miethe, P., Potthast, A., Rosenau, T., Liebner, F., 2010, Loading of bacterial cellulose aerogels with bioactive compounds by antisolvent precipitation with supercritical carbon dioxide, Macromolecular Symposia, 294(2):64-74

Katsila, T., Siskos, A. P., Tamvakopoulos, C., 2012, Peptide and Protein Drugs: The Study of their Metabolism and Catabolism by Mass Spectrometry, Mass Spectrometry Reviews, 31, 110-133

Khan M.S., Dwivedi, S., Priyadarshini, M., Tabrez, S., Siddiqui, M.A., Jagirdar, H., Al-Senaidy, A.M., AlKhedhairy, A.A., Musarrat, J., 2013, Ribosylation of bovine serum albumin induces ROS accumulation and cell death in cancer line (MCF-7), European Biophysics Journal, 42:811-8

Korsmeyer, R. W., Gurny, R., Doelker, E. M., Buri, P., \& Peppas, N. A. 1983, Mechanism of solute release from porous hydrophilic polymers. International Journal of Pharmaceutics, 15: 25-35

Muller, A., Ni, Z., Hessler, N., Wesarg, F., Muller, F.A., Kralisch, D., Fischer, D., 2013, The Biopolymer Bacterial Nanocellulose as Drug Delivery System: Investigation of Drug Loading and Release using the Model Protein Albumin, Journal of Pharmaceutical Sciences, 102 (2): 579-592

Ratnayake, W. R. A. P. J., Liyanage, A. L C. J., 2016a, Valorization of Waste Tender Coconut Water by Optimizing Growth Conditions for Nata-De-Coco Producing Culture System Isolated from Pineapple Peel Residue and Vinegar Starter Culture, ISEKI Food Conference, 4: 23-26

Ratnayake, W. R. A. P. J., Liyanage, A. L. C J., Jayasundera, A. C. A., 2016b, Bacterial Nano cellulose: a multifunctional nanomaterial, Science Council of Asia (SCA), 123, 87-95.

Ritger, P. L., Peppas, N. A. 1987, A simple equation for describing of solute release. I. Fickian and non-Fickian release from non-swellable devices in the form of slabs, spheres, cylinders or discs, Journal of Controlled Release, 5:23-36. 